\title{
Importance of Taking Into Account the Soil Stratification in Reproducing the Late-Time Features of Distant Fields Radiated by Lightning
}

\author{
Quanxin Li ${ }^{\circledR}$, Jianguo Wang ${ }^{\circledR}$, Member, IEEE, Farhad Rachidi ${ }^{\circledR}$, Fellow, IEEE, Marcos Rubinstein, Fellow, IEEE, \\ Antonio Šunjerga, Li Cai, and Mi Zhou, Member, IEEE
}

\begin{abstract}
In this paper, we present an analysis of the propagation effect along a lossy ground on the characteristics of lightning-generated electric fields, using simultaneous observations of lightning currents and radiated fields measured at nine different distances associated with rocket-triggered lightning. The triggered-lightning site is located in Conghua (Guangdong, China). The electric field waveforms were measured using the sensors belonging to the Foshan three-dimensional lightning location system that are located at distances from the triggered-lightning site ranging from 69 to $126 \mathrm{~km}$. The propagation path was over land and mainly over flat ground. The field sensors used had an overall bandwidth from $160 \mathrm{~Hz}$ to $1 \mathrm{MHz}$. It is shown that even though the early response of the field can be reproduced reasonably well by adjusting the ground electrical conductivity, the subsidiary peaks, and the late-time response of the fields cannot be satisfactorily reproduced assuming a homogeneous ground model. However, a two-layer soil model allows obtaining very good agreement between computed and measured waveforms for all the considered distances and events. Compared to the homogeneous ground case, the computed early-, intermediate-, and late-time response follows to a much better extent the experimental waveforms. We also provide a discussion on the influence of the computational model and parameters on the simulated results.
\end{abstract}

Index Terms-Distant electric fields, ground losses, horizontally stratified ground, return stroke, triggered lightning.

\section{INTRODUCTION}

$\mathbf{T}$ HE characteristics of lightning return-stroke electromagnetic fields, especially for natural lightning, have

Manuscript received February 22, 2018; revised April 18, 2018 and May 11, 2018; accepted May 11, 2018. This work was supported in part by the Public Welfare Industry Scientific Research Projects of Meteorological sector under Grant GYHY201306069, in part by the National Natural Science Foundation of China under Grant 51207116, and in part by the scholarship from the China Scholarship Council. (Corresponding authors: Jianguo Wang and Farhad Rachidi.)

Q. $\mathrm{Li}$ is with the School of Electrical Engineering, Wuhan University, Wuhan 430072, China, and also with the Swiss Federal Institute of Technology, Lausanne 1015, Switzerland (e-mail: liquanxin2014@hotmail.com).

J. Wang, Li Cai, and Mi Zhou are with the School of Electrical Engineering, Wuhan University, Wuhan 430072, China (e-mail: wjg@whu.edu.cn; caili@whu.edu.cn; zhoumi927@whu.edu.cn).

F. Rachidi and A. Sunjerga are with the Swiss Federal Institute of Technology, Lausanne 1015, Switzerland (e-mail: farhad.rachidi@epfl.ch; antonio. sunjerga@epfl.ch).

M. Rubinstein is with the University of Applied Sciences of Western Switzerland, Yverdon-les-bains 1400, Switzerland (e-mail: marcos.rubinstein@ heigvd.ch).

Color versions of one or more of the figures in this paper are available online at http://ieeexplore.ieee.org.

Digital Object Identifier 10.1109/TEMC.2018.2840702 extensively been reported in the literature (e.g., [1]-[4] ) These characteristics (waveshape, risetime, duration, zero-crossing time, etc.) depend obviously on the lightning discharge electrical and geometrical parameters. However, the ground electrical parameters over which electromagnetic fields propagate play also an important role in the lightning electromagnetic field waveshapes (e.g., [5]-[9]).

In the past years, significant efforts have been made to model the effect of the ground on the propagation of lightning-radiated electromagnetic fields (see, e.g., [10], [11]). Compared with dedicated algorithms (e.g., [12]) or numerical methods (e.g., [13]) that can be costly in terms of computation time and memory requirements, the use of simplified approaches (e.g., [5]-[10]) is particularly interesting when the electromagnetic fields need to be evaluated at a significant number of points, for instance, when evaluating the electromagnetic coupling to power networks. One of the first simplified approximations for the electromagnetic fields due to a vertical dipole above a homogeneous lossy ground is done by Norton [14]-[15]. Wait [16] showed that the concept of attenuation function and surface impedance can be used to represent the effect of a multilayered soil. Wait [17]-[19] and Hill and Wait [20] derived the attenuation function for the vertical electric field propagating over a horizontally stratified ground. Shoory et al. [21] examined the accuracy of Wait's formulations for a horizontally stratified ground using a numerical technique and found that Wait's formula is able to reproduce the vertical electric field peak and waveform with a reasonably good accuracy at far distances from the lightning channel. Other studies have considered the effect of a mixed propagation path or vertically stratified ground (e.g., [22] and [23]).

The aim of this paper is to analyze the propagation effect on the characteristics of lightning-generated electric fields. In particular, the effect of soil stratification on the radiated electromagnetic fields is assessed. For the analysis, we will use simultaneous observations of lightning currents and radiated fields measured at different distances associated with rocket-triggered lightning [24]. The present study demonstrates the importance of considering the soil stratification in reproducing the late-time features of distant fields radiated by lightning.

The paper is organized as follows. Section II briefly presents the experimental setup and measuring stations, as well as the obtained data. Section III describes the models and computational methods adopted in this paper. Section IV presents numerical 


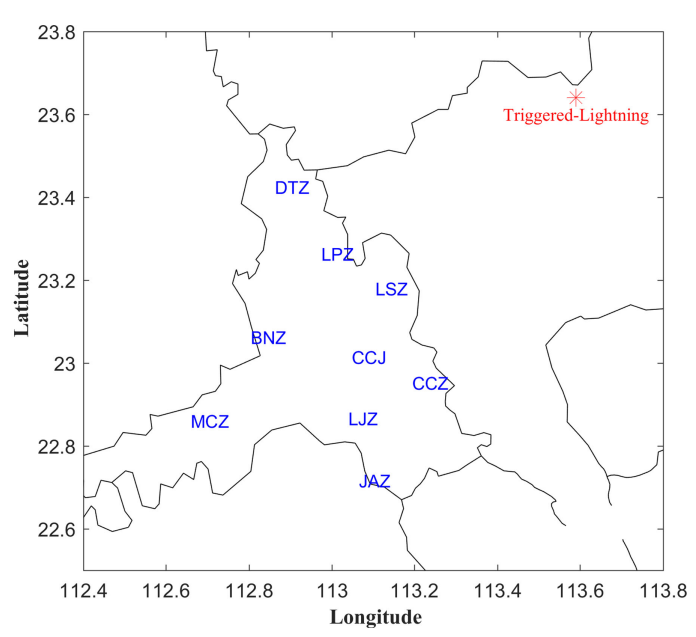

Fig. 1. Geographical location of the lightning triggering site in Conghua, Guangdong, and the nine sensors belonging to the lightning locating system in Foshan (FTLLS).

simulations and comparison with experimental data. The obtained results are commented and discussed in Section V. A summary and conclusions are given in Section VI.

\section{EXPERIMENTAL SETUP AND DATA}

\section{A. Experimental Setup}

The triggered-lightning site, which is located in Conghua, Guangdong, China, has been operational for more than a decade. Information about the triggered-lightning site is available in [24]. The Foshan three-dimensional lightning location system (FTLLS) has been installed and started its operation in the summer of 2013 [25]-[27]. The network contains nine stations labeled in Fig. 1 as LSZ, LPZ, DTZ, CCJ, BNZ, CCZ, LJZ, $\mathrm{JAZ}$, and MCZ. The stations are located at distances from the triggered-lightning site of, respectively, $69,73,74,85,87,100$, 101, 112, and $126 \mathrm{~km}$. The triggering site, also shown in Fig. 1, is located on the northeast of the nine sensors. The propagation path is over land and mainly over flat ground [26].

Wideband electric field measuring systems with a $3 \mathrm{~dB}$ bandwidth from $160 \mathrm{~Hz}$ to $1 \mathrm{MHz}$ are employed to measure the lightning electromagnetic fields at each station. The systems are equipped with analog integrators with a $1 \mathrm{~ms}$ decay time constant. Electric field signals produced by triggered-lightning discharges were digitized with a 10-MS/s sampling rate, 12-bit resolution, digital high-speed data acquisition card.

\section{B. Data}

The dataset is composed of simultaneous recordings of currents and multistation electric field waveforms associated with one negative triggered-lightning flash that occurred on June 3, 2014, at 6:43 AM (local time). The flash contains five return strokes, three of which (RS1, RS4, and RS5) were considered in this study.

\section{ANALYSIS METHOD}

\section{A. Return-Stroke Model}

The modified transmission line model with exponential decay (MTLE) model was adopted for the analysis [28], [29]. The current decay constant along the channel was assumed to be $\lambda=2 \mathrm{~km}$ and a return-stroke speed of $=1.5 \times 10^{8} \mathrm{~m} / \mathrm{s}$ was adopted in all the simulations. The adopted value for the current decay constant was inferred using experimental data [30]. This value is used in most of the studies using this model (e.g., [31]-[36]). The measured channel-base current waveform was represented using the sum of two Heidler's functions [37]

$$
\begin{aligned}
i(0, t) & =\frac{I_{01}}{\eta_{1}} \frac{\left(\frac{t}{\tau_{11}}\right)^{n_{1}}}{\left(\frac{t}{\tau_{11}}\right)^{n_{1}}+1} e^{-\frac{t}{\tau_{12}}}+\frac{I_{02}}{\eta_{2}} \frac{\left(\frac{t}{\tau_{11}}\right)^{n 2}}{\left(\frac{t}{\tau_{21}}\right)^{n_{2}}+1} e^{-\frac{t}{\tau_{22}}} \\
\eta_{1} & =\exp \left(-\frac{\tau_{11}}{\tau_{12}}\left(n_{1} \frac{\tau_{12}}{\tau_{11}}\right)^{1 / n_{1}}\right) \\
\eta_{2} & =\exp \left(-\frac{\tau_{21}}{\tau_{22}}\left(n_{1} \frac{\tau_{22}}{\tau_{21}}\right)^{1 / n_{2}}\right) .
\end{aligned}
$$

The parameters of (1) were determined for each return stroke using a genetic algorithm [38]. The reason why the measured current was represented by analytical functions is that the use of the raw data, which includes noise could cause numerical issues. Fig. 2 presents the measured current waveforms associated with the three considered return-stroke pulses along (to which we refer in this study as RS1, RS4, and RS5) with their analytical representations using Heidler's functions. The determined parameters of the functions for each waveform are given in Table I.

\section{B. Electric Field Computation Model}

Three different approaches will be used in this study to model the ground plane in the computation of the electric fields at various distances: a perfectly conducting ground plane, a homogeneous finitely conducting ground plane, and a two-layer stratified ground.

1) Perfectly Conducting Ground: Fig. 3 presents the geometry adopted for the calculation of lightning electric field. The expression for the vertical electric field radiated by a vertical channel above a perfectly conducting ground is given by (e.g., [10])

$$
\begin{aligned}
& e_{z, p}(d, z, t)=\frac{1}{2 \pi \varepsilon^{\circ}} \int_{0}^{H(d, z, \varphi, t)} \\
& \times\left[\begin{array}{l}
\frac{2\left(z-z^{\prime}\right)^{2}-d^{2}}{R^{5}\left(z^{\prime}\right)} \int_{R\left(z^{\prime}\right) / c+z^{\prime} / c}^{t} i\left(z^{\prime}, \tau-\frac{R}{c}\right) d \tau \\
+\frac{2\left(z-z^{\prime}\right)^{2}-d^{2}}{c R^{4}\left(z^{\prime}\right)} i\left(z^{\prime}, t-R\left(z^{\prime}\right) / c\right) \\
-\frac{d^{2}}{c^{2} R^{3}\left(z^{\prime}\right)} \frac{\partial i\left(z^{\prime}, t-R\left(z^{\prime}\right) / c\right)}{\partial t}
\end{array}\right] d z^{\prime} \\
& -\frac{1}{2 \pi \varepsilon^{\circ}} \frac{d^{2}}{c^{2} R^{3} H(d, z, \varphi, t)} \\
& \times i\left(H(d, z, \varphi, t), \frac{H(d, z, \varphi, t)}{v}\right) \frac{d H(d, z, \varphi, t)}{d t}
\end{aligned}
$$




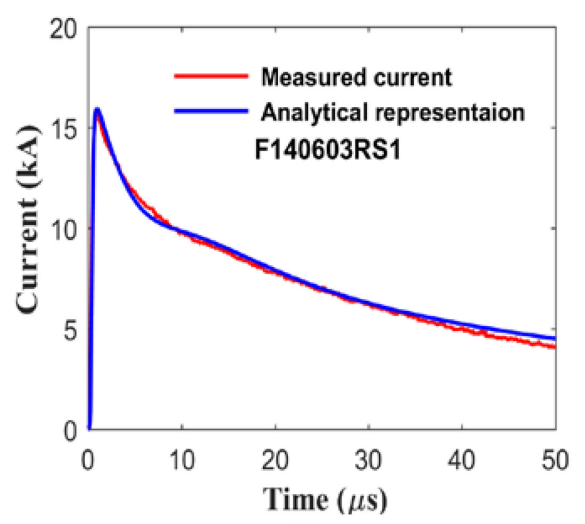

(a)

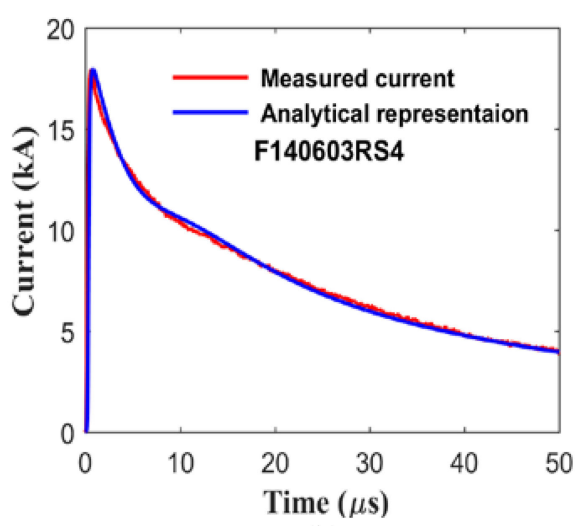

(b)

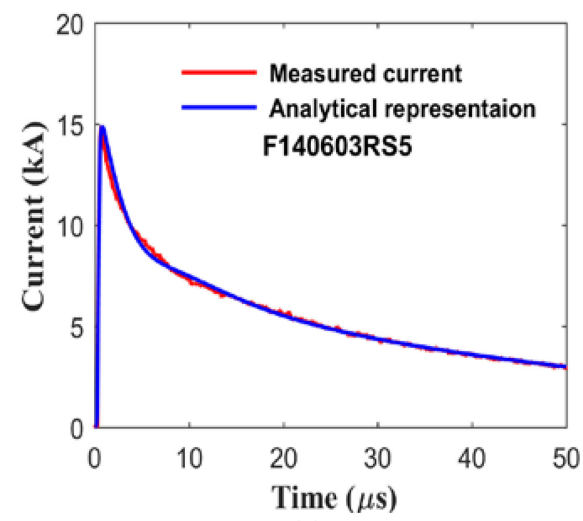

(c)

Fig. 2. Measured current waveforms associated with the three selected return stokes (solid blue line) and their analytical representations using Heidler's functions (solid red line). (a) RS1. (b) RS4. (c) RS5.

TABLE I

PARAMETERS OF HEIDLER'S FUNCTIONS USED TO REPRESENT THE RETURN STROKE CURRENT WAVEFORMS

\begin{tabular}{ccccccccc}
\hline \hline Lightning return stroke & $I_{01}(k A)$ & $\tau_{11}(\mu s)$ & $\tau_{12}(\mu s)$ & $n_{1}$ & $I_{02}(k A)$ & $\tau_{21}(\mu s)$ & $\tau_{22}(\mu s)$ & $n_{2}$ \\
\hline RS1 & 16.0 & 0.501 & 9.6 & 5 & 5.6 & 10.0 & 77 & 3 \\
RS4 & 18.0 & 0.359 & 8.9 & 5 & 5.9 & 9.5 & 60 & 3 \\
RS5 & 15.0 & 0.417 & 6.1 & 6 & 5.0 & 8.0 & 55 & 3 \\
\hline \hline
\end{tabular}

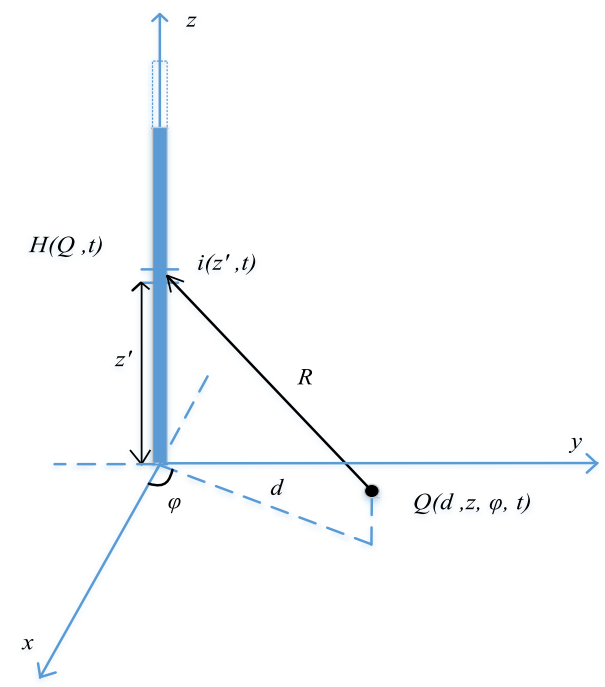

Fig. 3. Geometry for the calculation of the lightning electromagnetic field.

where $i\left(z^{\prime}, t\right)$ is the current in the return-stroke channel, $H(d, z, \varphi, t)$ is the apparent height of the wavefront as seen by an observer at $Q$ at time $t$. $R$ is the distance from a channel segment $d z^{\prime}$ at height $z^{\prime}$ to the observation point, $d$ is the horizontal distance between the channel base and the observation point, $c$ is the speed of light, $v$ is return-stroke speed, and $\varepsilon_{0}$ is the permittivity of free space. The second subscript $p$ holds for the field above a perfect ground. The last term in (2) is the so-called turn-on term field component accounting for a possible discontinuity at the return-stroke wavefront, as introduced and discussed by Le Vine and Meneghini [39], Rubinstein and Uman [40], [41], Le Vine and Willett [42], Thottappillil and Rakov [43], [44], Thottappillil et al. [45], [46], and Pavanello et $a l$. [47]. The current distribution predicted by the MTLE model we are using in this paper does not feature any discontinuity at the wavefront, and therefore, this last term is equal to zero.

2) Homogeneous Finitely Conducting Ground: The vertical electric field above a homogeneous lossy ground can be written in the time domain as (e.g., [10])

$$
e_{z}(d, z, t)=e_{z, p}(d, z, t) * f(t)
$$

where $f(t)$ is the attenuation function accounting for the propagation effects along a lossy half-space. Expressions for the attenuation function and ground surface impedance can be obtained in the frequency domain and the corresponding time-domain expression can be derived using inverse Fourier transforms, i.e.,

$$
f(t)=F^{-1}[F(j \omega)]
$$

where $\omega$ is the angular frequency. Equation (3) can be equivalently expressed in the frequency domain as

$$
E_{z}(d, z, j \omega)=E_{z, p}(d, z, j \omega) F(j \omega) .
$$

The expression for the attenuation function above a homogeneous ground derived by Wait [18] is as follows:

$$
F(j \omega)=1-j \sqrt{\pi p} e^{-p} \operatorname{erfc}(j \sqrt{p})
$$

where $\operatorname{erfc}$ is the complementary error function [19] and $p$ is the numerical distance defined as

$$
p=-0.5 \gamma_{0} d \Delta^{2}
$$




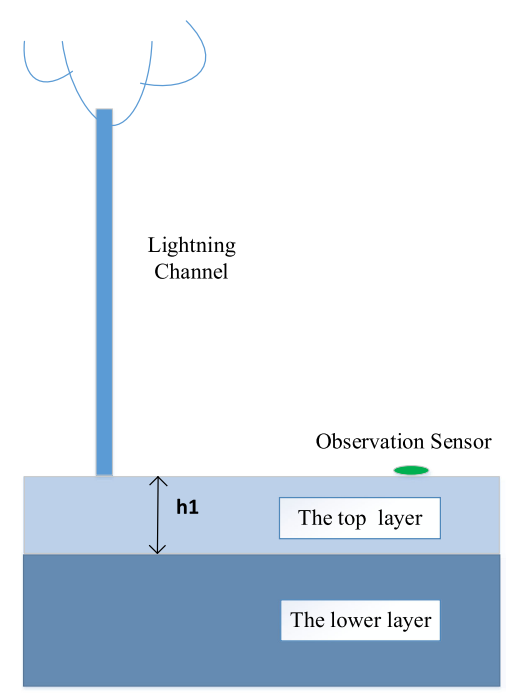

Fig. 4. Geometry for the calculation of the lightning electromagnetic field above a two-layer soil.

in which $\gamma_{0}$ is the free-space wavenumber defined as

$$
\gamma_{0}=j \omega \sqrt{\mu_{0} \varepsilon_{0}}
$$

where $\mu_{0}$ is the permeability of vacuum. $\Delta$ is the normalized surface impedance of the homogeneous ground given by

$$
\Delta=\frac{Z(j \omega)}{\sqrt{\mu_{0} / \varepsilon_{0}}}
$$

in which the homogeneous ground surface impedance is given by

$$
Z(j \omega)=\sqrt{\frac{j \omega \mu_{0}}{\sigma+j \omega \varepsilon_{0} \varepsilon_{r}}} .
$$

3) Two-Layer Stratified Ground: Fig. 4 shows the geometry of a two-layer stratified soil. The first layer is characterized by a vertical depth $h 1$, and electrical parameters $\sigma_{1}$ and $\varepsilon_{r 1}$. The second layer is characterized by electrical parameters $\sigma_{2}$ and $\varepsilon_{r 2}$.

Wait et al. [10]-[16] derived the expression for the attenuation function of a stratified ground given by

$$
F_{s t r}(j \omega)=1-j \sqrt{\pi p_{s t r}} e^{-p_{s t r}} \operatorname{erf} c\left(j \sqrt{p_{s t r}}\right)
$$

in which the numerical distance $p_{\text {str }}$ is defined as

$$
p_{s t r}=-0.5 \gamma_{0} d \Delta_{s t r}^{2}
$$

In (12), $\Delta_{s t r}$ is the normalized surface impedance of the two-layer ground given by

$$
\Delta_{s t r}=\frac{Z_{s t r}(j \omega)}{\sqrt{\left(\mu_{0} / \varepsilon_{0}\right)}}
$$

where

$$
Z_{s t r}=\sqrt{\frac{\varepsilon_{0}}{\mu_{0}}} K_{1} \frac{K_{2}+K_{1} \tanh \left(u_{1} h_{1}\right)}{K_{1}+K_{2} \tanh \left(u_{1} h_{1}\right)}
$$

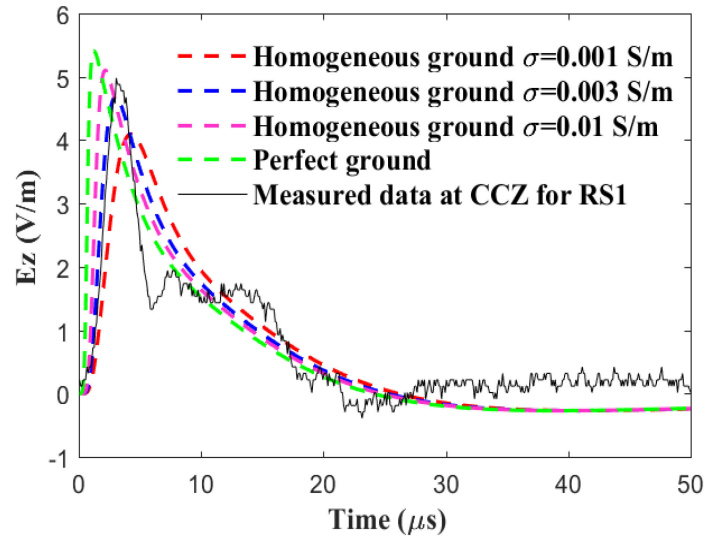

Fig. 5. Dashed color lines describe the simulation results for the homogeneous and for the perfect ground cases. The black solid line indicates the measured vertical fields at station of CCZ for the first return-stroke in flash F140603.

is the surface impedance of a two-layer horizontally stratified ground, and

$$
\begin{aligned}
& K_{1}=\frac{u_{1}}{\sigma_{1}+j \omega \varepsilon_{0} \varepsilon_{r 1}} \\
& K_{2}=\frac{u_{2}}{\sigma_{2}+j \omega \varepsilon_{0} \varepsilon_{r 2}} \\
& u_{1}=\sqrt{\gamma_{1}^{2}-\gamma_{0}^{2}} \\
& u_{2}=\sqrt{\gamma_{2}^{2}-\gamma_{0}^{2}} .
\end{aligned}
$$

In (17) and (18), the wave numbers in each ground layer are given by

$$
\gamma_{1}=\sqrt{j \omega \mu_{0}\left(\sigma_{1}+j \omega \varepsilon_{0} \varepsilon_{r 1}\right)}
$$

and

$$
\gamma_{2}=\sqrt{j \omega \mu_{0}\left(\sigma_{2}+j \omega \varepsilon_{0} \varepsilon_{r 2}\right)} .
$$

\section{SimUlation AND COMPARISON With EXPERIMENT DATA}

We consider the lightning flash occurred on June 3, 2014, at 6:43 AM, as shown in Fig. 2. We have selected three return strokes (labeled RS1, RS4, and RS5) for the analysis. Similar simulations were performed for the two other strokes but they were not shown for the sake of brevity.

Fig. 5 presents the simulation results obtained assuming either a perfect or a homogeneous lossy ground with different ground electrical conductivities, and their comparison with the corresponding measured waveforms. In Fig. 5, the presented waveforms correspond to the field at Station CCZ that is located at a distance of $85 \mathrm{~km}$ with respect to the stroke location. It can be seen that, even though the early response of the field can be reproduced reasonably well by adjusting the ground electrical conductivity, the subsidiary peaks and the late-time response of the field cannot be satisfactorily reproduced assuming a homogeneous ground model.

The simulation results assuming a two-layer model for the ground are shown in Fig. 6 for all the stations and all the three return strokes. Each column presents the results for one return 


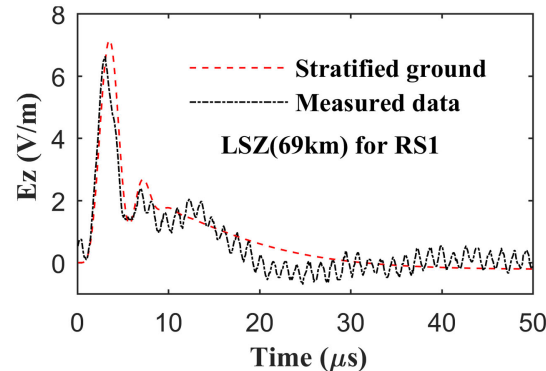

(a1)

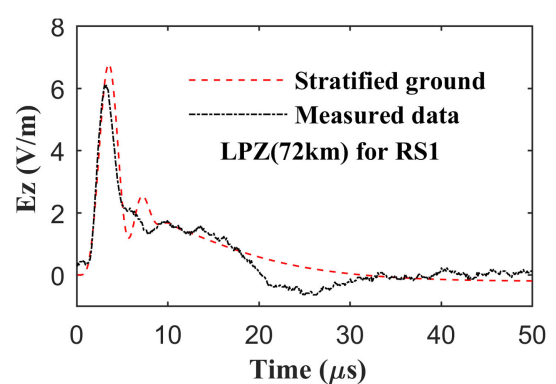

(b1)

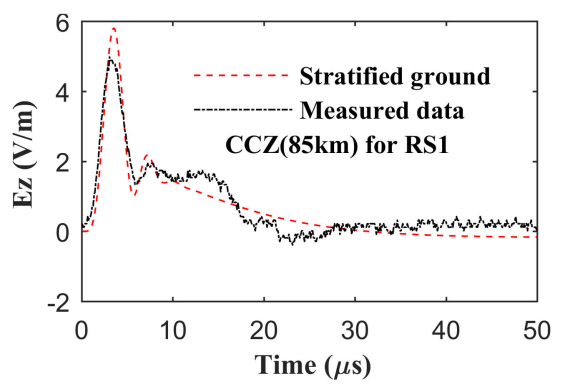

(c1)

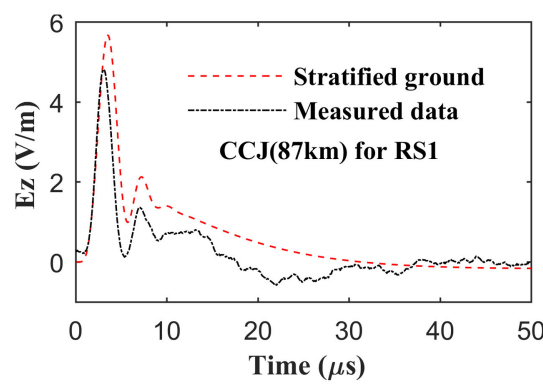

(d1)

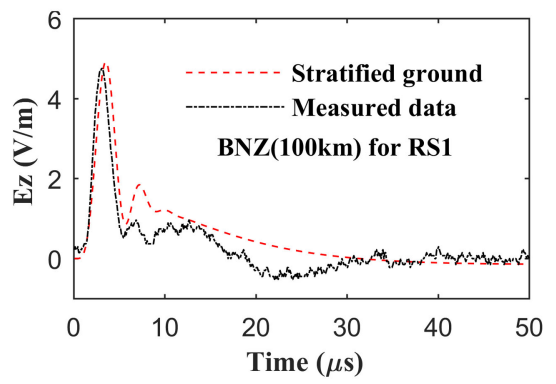

(e1)

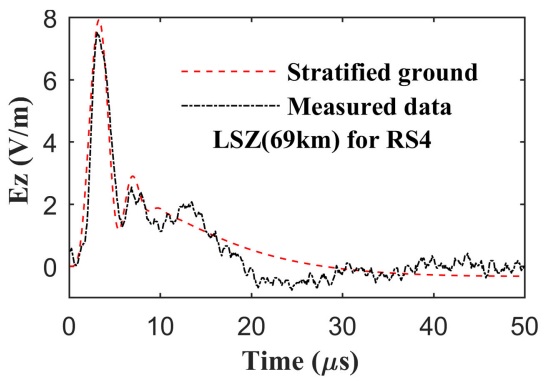

(a2)

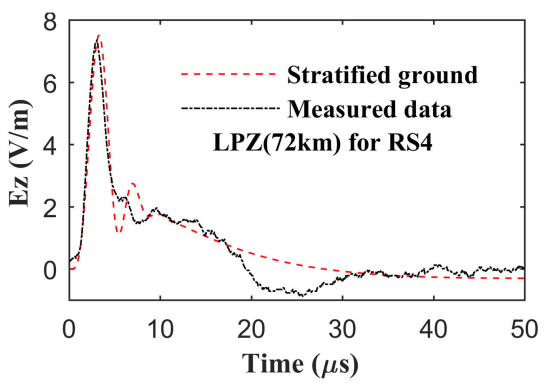

(b2)

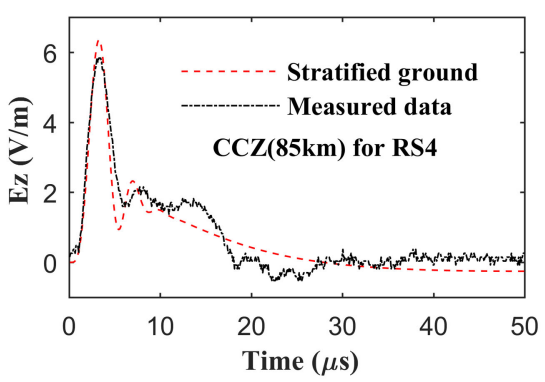

(c2)

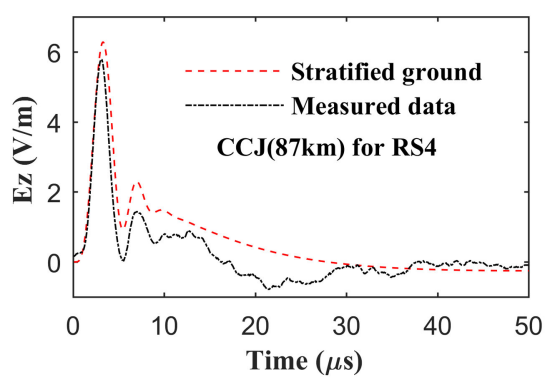

(d2)

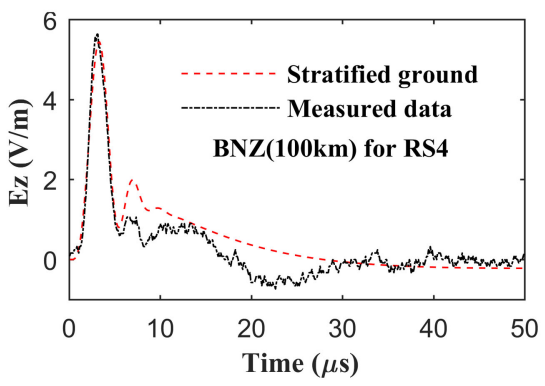

(e2)

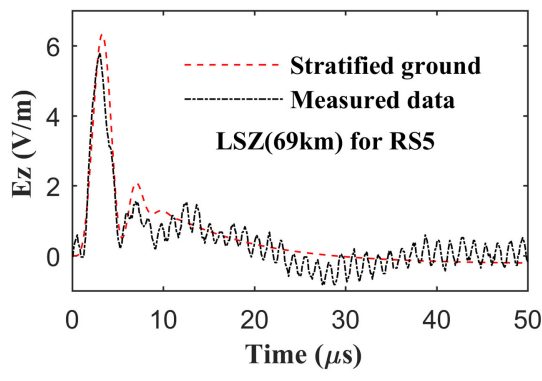

(a3)

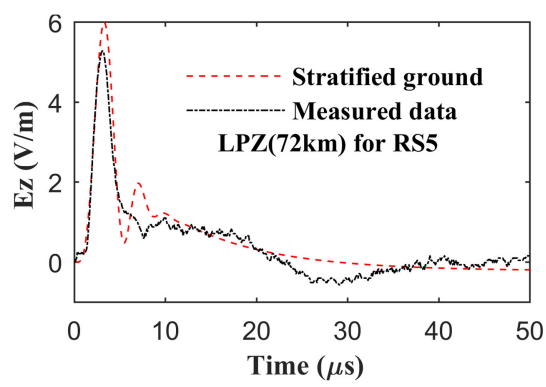

(b3)

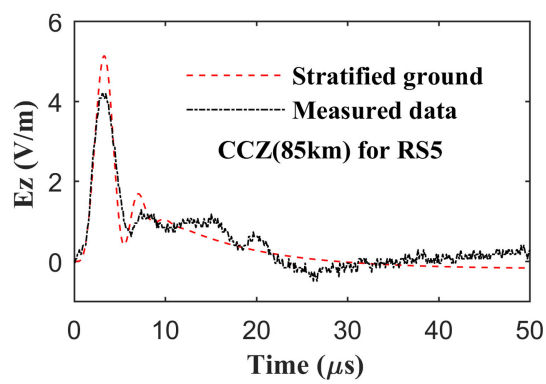

(c3)

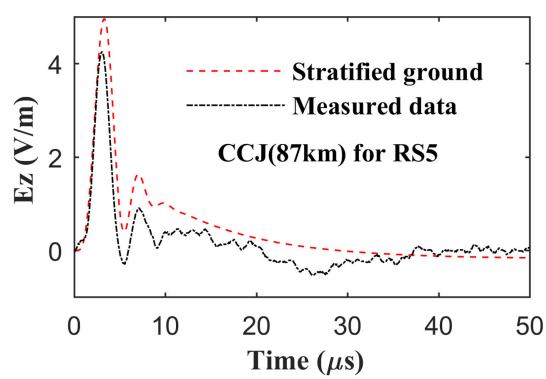

(d3)

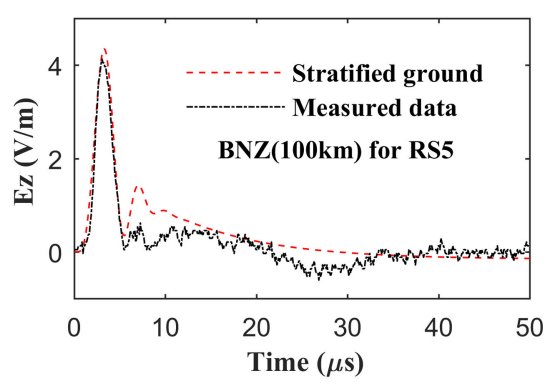

(e3)

Fig. 6. Simulation results from the two-layer soil for the three considered cases. The dashed red line and black dotted line represent the stratified ground simulation and measured data, respectively. (a1)-(g1) Left-hand column present simulation results from multiple stations for RS1 for RS1 in flash F140603. (a2)-(g2) Middle column corresponds to RS4. (a3)-(g3) Right-hand column corresponds to RS5. 


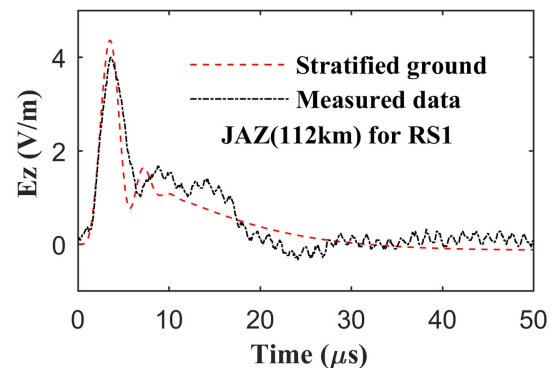

(f1)

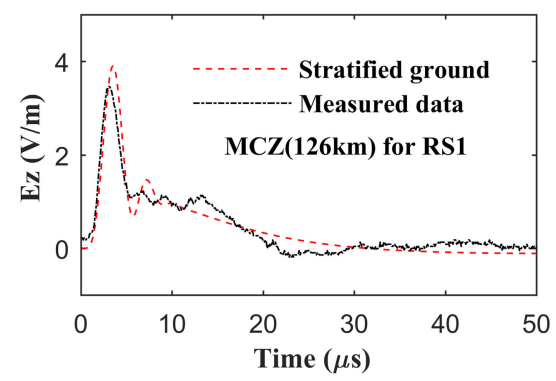

(g1)

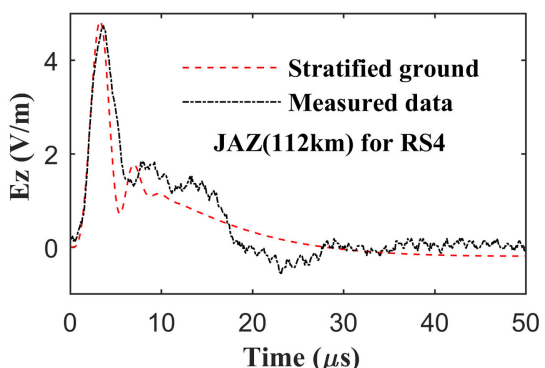

(f2)

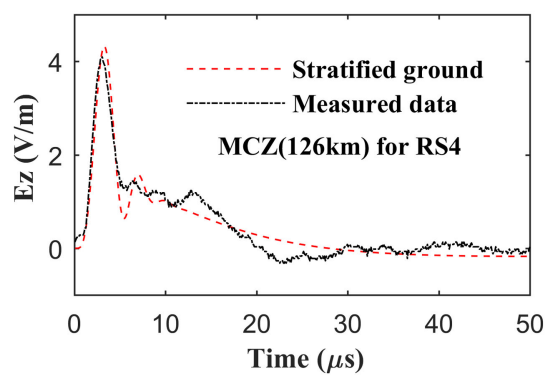

(g2)

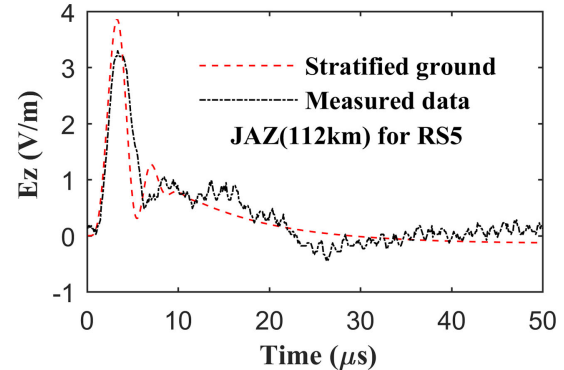

(f3)

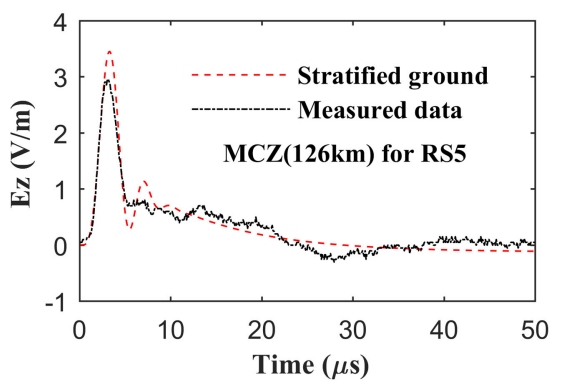

(g3)

Fig. 6. Continued.

stroke, for which electric field waveforms (calculated and measured) are presented for stations LSZ, LPZ, CCZ, CCJ, BNZ, JAZ, and MCZ (shortest to farthest) from the top to the bottom. The ground parameters $\sigma_{1}, \sigma_{2}, \varepsilon_{r 1}, \varepsilon_{r 2}$, and the height of the top layer $h 1$ were, respectively, set to $0.001 \mathrm{~S} / \mathrm{m}, 4,5,80$, and $15.5 \mathrm{~m}$, for all the considered observation points. These values were determined in order to obtain the best match with the experimental data. The inferred parameters can be considered as reasonable. Indeed, evidence of a multilayer structure of the soil in China can be found in [48]. Similar parameters have been adopted in other studies considering the same geographical region [49]. However, this point calls for further research. Considering the same ground parameters along the path of propagation for each site is certainly an approximation. In reality, a better knowledge of the ground electrical parameters should be gained for each field measurement site. Note also that the adopted value for the top layer conductivity $(0.001 \mathrm{~S} / \mathrm{m})$ is consistent with available data [50].

It can be seen that a two-layer soil model allows obtaining very good agreement between computed and measured waveforms for all the considered distances and events. Compared to the homogeneous ground case, the computed early-, intermediate-, and late-time response follows to a much better extent the experimental waveforms. The observed discrepancies (for example at CCJ and BNZ stations) might be due to the variation of the soil electrical parameters along the considered paths.

\section{DISCUSSION}

A discussion is in order on the influence of various parameters adopted for the simulations, namely the adopted returnstroke model, the values for the ground conductivity of the top

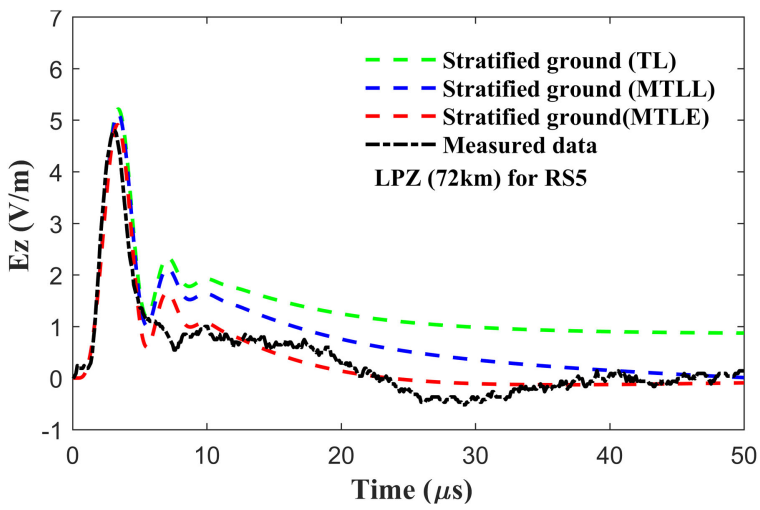

Fig. 7. Influence of the return-stroke models on simulated results. $\varepsilon_{r 1}=$ $5, \varepsilon_{r 2}=80, \sigma_{1}=0.001 \mathrm{~S} / \mathrm{m}, \sigma_{2}=4 \mathrm{~S} / \mathrm{m}, \mathrm{h} 1=15.5 \mathrm{~m}$.

and lower layer, depth of the top layer, and the return-stroke speed.

1) Return-stroke model: Fig. 7 shows the simulation results for the station LPZ using three different return-stroke models: MTLE [28]-[29], TL [51], and MTLL [52]. It can be seen that, as far as the early-time response of the field is concerned, the three models provide very similar results. The fact that the TL model fails in reproducing the late-time response is well known and is due to the absence of any attenuation of the current pulse along the channel (e.g., [53]). In summary, it can be said that the adopted return-stroke model will affect to some extent the results.

2) Conductivity of the top layer: Fig. 8 shows the simulation results considering three different conductivities for the top ground layer associated with return-stroke RS5 in Fig. 2(c). The relative permittivity was set to $\varepsilon_{r 1}=5$. The conductivity and the relative permittivity of the second 


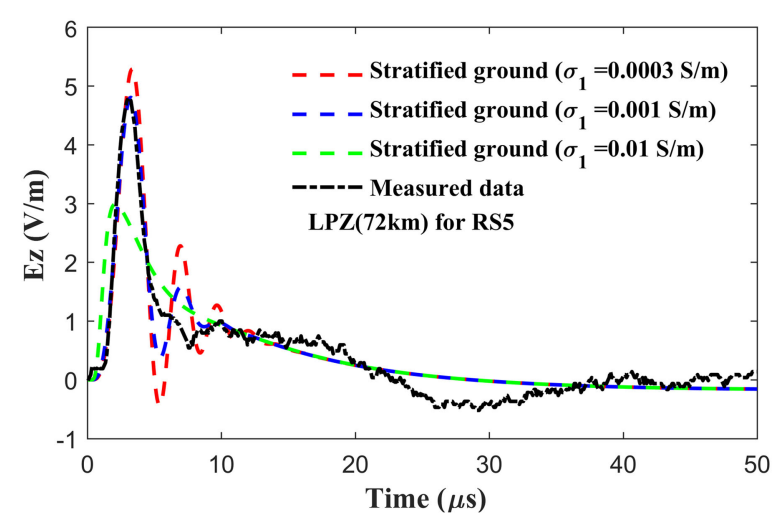

Fig. 8. Influence of the conductivity of the top layer on simulated results. $\varepsilon_{r 1}=5, \varepsilon_{r 2}=80, \sigma_{2}=4 \mathrm{~S} / \mathrm{m}, h_{1}=15.5 \mathrm{~m}$.

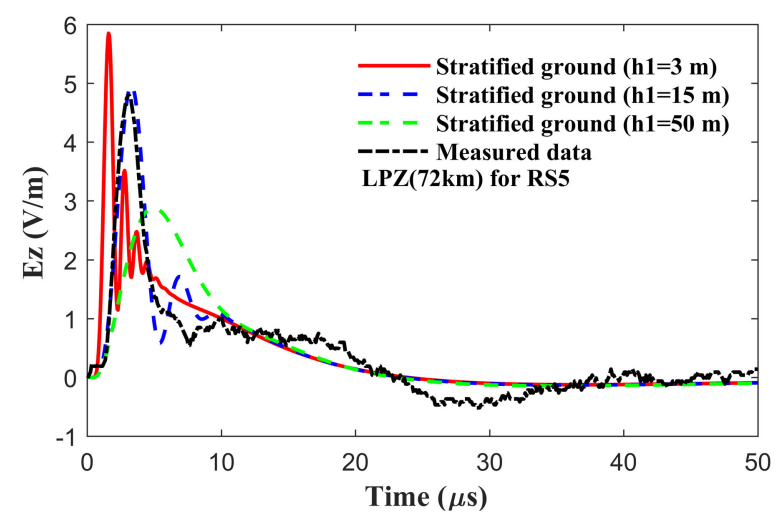

Fig. 9. Influence of the depth of the top layer on simulated results. $\varepsilon_{r 1}=$ $5, \varepsilon_{r 2}=80, \sigma_{1}=0.001 \mathrm{~S} / \mathrm{m}, \sigma_{2}=4 \mathrm{~S} / \mathrm{m}$.

layer were set, respectively, to $\sigma_{2}=4 \mathrm{~S} / \mathrm{m}$ and $\varepsilon_{r 2}=80$. The depth of first layer was set to $h 1=15.5 \mathrm{~m}$. As expected, it can be seen that the conductivity of the top layer affects essentially the early-time and intermediate-time response of the field. A decrease of the conductivity results in an increase of the peak electric field, which can be higher than the peak corresponding to the perfectly ground case. In addition, for low conductivities, the field waveform has an oscillatory behavior featuring subsidiary peaks. These results are consistent with previous studies (e.g., Shoory et al. [21]). As discussed in [5], when the conductivity of the top layer is lower than that of the lower layer, the attenuation function can be larger than unity for certain frequencies.

3) Depth of the top layer: The effect of the depth of the top layer is illustrated in Fig. 9, in which the electric field was evaluated considering three different values for this parameter, namely 3,15 , and $50 \mathrm{~m}$. The ground electrical parameters are $\varepsilon_{r 1}=5, \varepsilon_{r 2}=80, \sigma_{1}=$ $0.001 \mathrm{~S} / \mathrm{m}$, and $\sigma_{2}=4 \mathrm{~S} / \mathrm{m}$. It can be seen that the frequency of oscillations and the field peaks depend strongly on the depth of the top layer. The larger the depth, the smaller the peak and the oscillation frequency. For large values of the top layer depth (50 $\mathrm{m}$ or higher), the oscillation disappears. In this case, the depth of the top

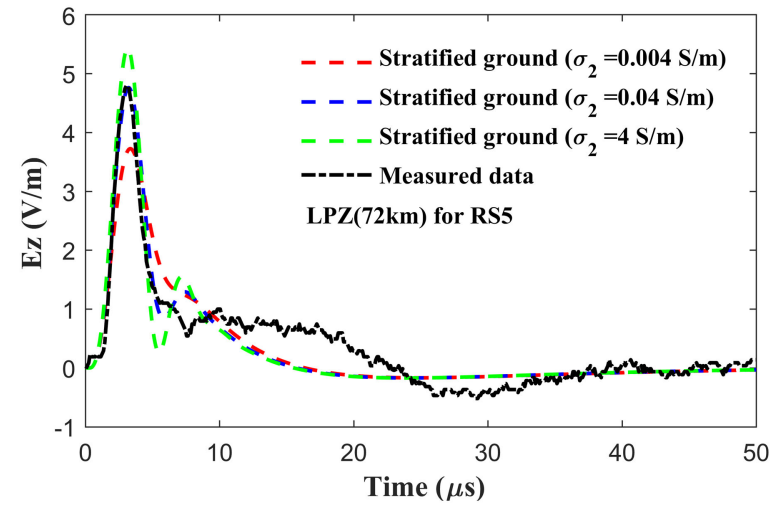

Fig. 10. Influence of the conductivity of the lower layer on simulated results. $\varepsilon_{r 1}=5, \varepsilon_{r 2}=80, \sigma_{2}=4 \mathrm{~S} / \mathrm{m}, \mathrm{h} 1=15.5 \mathrm{~m}$.

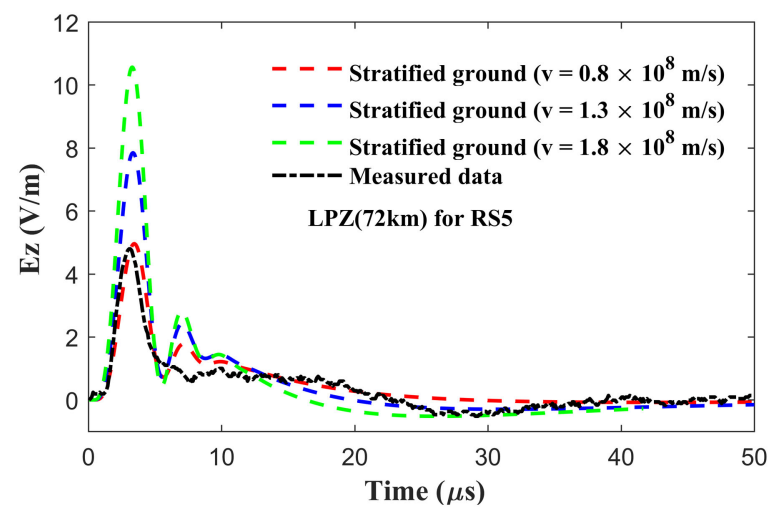

Fig. 11. Influence of the return-stroke speed on simulated results. $\varepsilon_{r 1}=$ $5, \varepsilon_{r 2}=80, \sigma_{1}=0.001 \mathrm{~S} / \mathrm{m}, \sigma_{2}=4 \mathrm{~S} / \mathrm{m}, \mathrm{h} 1=15.5 \mathrm{~m}$.

layer is much larger than the skin depth for the relevant frequencies, and the stratified ground behaves as a homogeneous ground with upper layer parameters [5].

4) Conductivity of the lower layer: Fig. 10 shows the simulations considering three different conductivities for the lower layer, namely $0.0004,0.04$, and $4 \mathrm{~S} / \mathrm{m}$. In agreement with [5], it can be seen that the subsidiary peaks resulting from the oscillatory behavior appear only when the conductivity of the lower layer is greater than that of the top layer.

5) Return-stroke speed: The effect of the return-stroke speed is illustrated in Fig. 11, considering three different values, namely $0.8 \times 10^{8}, 1.3 \times 10^{8}$, and $1.8 \times 10^{8} \mathrm{~m} / \mathrm{s}$. It can be seen that the return-stroke speed affects essentially the early-time response of the field and its peak value. At the considered distant location, the peak field is essentially proportional to the value of the return-stroke speed [54].

It is worth noting that the late-time features of the distant electric fields may also be influenced by other effects, such as attenuation and dispersion of the propagating current along the lightning channel as discussed in Shao et al. [55] and Shoory et al. [35], channel tortuosity [56], return-stroke speed, and return-stroke model inaccuracies. Furthermore, the fact that other factors such as local effects at the field-measuring stations could affect the subsidiary peaks cannot be completely 
ruled out. However, the fact that a two-layer soil model allows us to reproduce reasonably well the fields measured at nine different stations located in different geographical locations is an indication that the stratified soil plays at least an important role in the late-time response of the field.

\section{SUMMARY AND CONCLUSION}

We presented an analysis of the propagation effect along a lossy ground on the characteristics of lightning-generated electric fields, using simultaneous observations of lightning return-stroke currents and vertical radiated fields measured at nine different distances from rocket-triggered lightning. The triggered-lightning site was located in Conghua (Guangdong, China). The electric field waveforms were measured using the sensors belonging to the FTLLS, which were located at distances from the triggered-lightning site ranging from 69 to $126 \mathrm{~km}$. The propagation path is over land and mainly over flat ground. The field sensors have an overall bandwidth from $160 \mathrm{~Hz}$ to $1 \mathrm{MHz}$.

It was shown that, even though the early response of the fields can be reproduced reasonably well by adjusting the ground electrical conductivity of a single-layer ground model, the subsidiary peaks and the late-time response of the fields cannot be satisfactorily reproduced assuming a homogeneous ground model. However, it was shown that a two-layer soil model allows obtaining very good agreement between computed and measured waveforms for all the considered distances and events. Compared to the homogeneous ground case, the computed early-, intermediate-, and late-time response follows to a much better extent the experimental waveforms. We also provided a discussion on the influence of computational model and parameters on the simulated results.

\section{ACKNOWLEDGMENT}

The authors would like to thank to the anonymous reviewers for their precious comments and suggestions on the manuscript and all the members of Guangzhou Field Experiment Site for Triggered Lightning at Conghua in Guangdong Province.

\section{REFERENCES}

[1] Y. T. Lin et al., "Characterization of lightning return stroke electric and magnetic fields from simultaneous two station measurements," J. Geophys. Res., vol. 84, pp. 6307-6314, 1979.

[2] C. D. Weidman and E. P. Krider, "The fine structure of lightning return stroke waveforms," J. Geophys. Res., vol. 83, pp. 6239-6247, 1978.

[3] M. A. Haddad, V. A. Rakov, and S. A. Cummer, "New measurements of lightning electric fields in Florida: Waveform characteristics, interaction with the ionosphere, and peak current estimates," J. Geophys. Res., vol. 117, 2012, Art. no. D10101.

[4] V. Cooray and S. Lundquist, "Characteristics of the radiation fields from lightning in Sri Lanka in the tropics," J. Geophys. Res., vol. 90, pp. 6099-6109, 1985.

[5] V. Cooray, The Lightning Flash, 2nd ed. London, U.K.: Inst. Eng. Technol., 2014, ch.11.

[6] V. Cooray, "Effects of propagation on the return stroke radiation fields," Radio Sci., vol. 22, pp. 757-768, 1987.

[7] V. Cooray and Y. Ming, "Propagation effects on the lightning generated electromagnetic fields for homogeneous and mixed sea land paths," $J$ Geophys. Res., vol. 99, pp. 10641-10652, 1994

[8] Y. Ming and V. Cooray, "Propagation effects caused by a rough ocean surface on the electromagnetic fields generated by lightning," Radio Sci., vol. 29, pp. 73-85, 1994.
[9] V. Cooray, "Propagation effects due to finitely conducting ground on lightning-generated magnetic fields evaluated using Sommerfeld's integrals," IEEE Trans. Electromagn. Compat., vol. 51, no. 3, pp. 526-531, Jun. 2009.

[10] A. Shoory, F. Rachidi, and V. Cooray, "Propagation effects on electromagnetic fields generated by lightning return strokes: Review of simplified formulas and their validity assessment," in Lightning Electromagnetics. Stevenage, U.K.: Inst. Eng. Technol., 2012, ch. 12, pp. 485-513.

[11] V. Cooray and K. L. Cummins, "Propagation effects caused by stratified ground on electromagnetic fields of return strokes," in Proc. 20th Int. Lightning Detect. Conf. 2nd Int. Lightning Meteorol. Conf., Tucson, AZ, USA, 2008, pp. 1-11.

[12] V. A. Rakov and F. Rachidi, "Overview of recent progress in lightning research and lightning protection," IEEE Trans. Electromagn. Compat., vol. 51, no. 3, pp. 428-442, Aug. 2009.

[13] A. Mimouni, F. Rachidi, and Z. E. Azzouz, "A finite-difference timedomain approach for the evaluation of electromagnetic fields radiated by lightning strikes to tall structures," J. Elect., vol. 66, pp. 504-513, Sep. 2008.

[14] K. A. Norton, "The propagation of radio waves over the surface of the earth and in the upper atmosphere-Part I," in Proc. Inst. Radio Eng., 1936, vol. 24, pp. 1367-1387.

[15] K. A. Norton, "The propagation of radio waves over the surface of the earth and in the upper atmosphere-Part II," in Proc. Inst. Radio Eng., 1937, vol. 25, pp. 1203-1236.

[16] J. R. Wait, "The ancient and modern history of EM ground-wave propagation," IEEE Antennas Propag. Mag., vol. 40, no. 5, pp. 7-24, Oct. 1998.

[17] J. R. Wait, Electromagnetic Waves in Stratified Media. New York, NY, USA: IEEE Press, 1996.

[18] J. R. Wait, "Radiation from a vertical electric dipole over a stratified ground," IRE Trans. Antennas Propag., vol. AP-1, no. 1, pp. 9-11, Jul. 1953.

[19] J. R. Wait, "On the theory of transient electromagnetic sounding over a stratified earth," Can. J. Phys., vol. 50, pp. 1055-1061, Jun. 1972.

[20] D. A. Hill and J. R. Wait, "HF radio wave transmission over sea ice and remote sensing possibilities," IEEE Trans. Geosci. Remote Sens., vol. GE-19, no. 4, pp. 204-209, Oct. 1981.

[21] A. Shoory, A. Mimouni, F. Rachidi, V. Cooray, R. Moini, and S. H. Sadeghi, "Validity of simplified approaches for the evaluation of lightning electromagnetic fields above a horizontally stratified ground," IEEE Trans. Electromagn. Compat., vol. 52, no. 3, pp. 657-663, Apr. 2010.

[22] A. Shoory, A. Mimouni, F. Rachidi, V. Cooray, and M. Rubinstein, "On the accuracy of approximate techniques for the evaluation of lightning electromagnetic fields along a mixed propagation path," Radio Sci., vol. 46, 2011, Art. no. RS2001.

[23] Q. Zhang, D. Li, Y. Zhang, J. Gao, and Z. Wang, "On the accuracy of Wait's formula along a mixed propagation path within $1 \mathrm{~km}$ from the lightning channel," IEEE Trans. Electromagn. Compat., vol. 54, no. 5, pp. 1042-1047, Oct. 2012.

[24] Y. J. Zhang, "Experiments of artificially triggered lightning and its application in Conghua, Guangdong, China," Atmos. Res., vol. 117, pp. 330-343, 2012.

[25] L. Cai, "Ground-based VLF/LF three dimensional total lightning location technology," (in Chinese), Ph.D. dissertation, School Elect. Eng., Wuhan Univ., Wuhan, China, 2013.

[26] L. Cai, J. Wang, Q. Li, and Y. Fan, "The foshan total lightning location system in china and its initial result," presented at the 10th Asia-Pacific Conf. Lightning Protection (APL 2017), Krabi, Thailand, 2017.

[27] W. Jianguo et al., "Far electric field waveform in triggered lightning," presented at the 10th Asia-Pacific. Conf. Lightning Protection (APL 2017), Krabi, Thailand, 2017.

[28] C. A. Nucci, C. Mazzetti, F. Rachidi, and M. Ianoz, "On lightning return stroke models for LEMP calculations," presented at the 19th Int. Conf. Lightning Protection, Graz, Austria, 1988.

[29] F. Rachidi and C. A. Nucci, "On the Master, Uman, Lin, Standler and the modified transmission line lightning return stroke current models," $J$. Geophys. Res., vol. 95, pp. 20389-20393, 1990.

[30] C. A. Nucci and F. Rachidi, "Experimental validation of a modification to the transmission line model for LEMP calculation," in Proc. 8th Symp. Tech. Exhib. Electromagn. Compat., Zurich, Switzerland, Mar. 1989, pp. 389-394.

[31] A. Mimouni, F. Rachidi, and M. Rubinstein, "Electromagnetic fields of a lightning return stroke in presence of a Stratified Ground," IEEE Trans. Electromagn. Compat., vol. 56, no. 2, pp. 413-418, Apr. 2014. 
[32] D. Li, M. Rubinstein, F. Rachidi, G. Diendorfer, W. Schulz, and G. Lu, "Location accuracy evaluation of ToA-based lightning location systems over mountainous terrain," J. Geophys. Res., vol. 122, pp. 11760-11775, 2017.

[33] F. Rachidi et al., "Current and electromagnetic field associated with lightning-return strokes to tall towers," IEEE Trans. Electromagn. Compat., vol. 43, no. 3, pp. 356-367, Aug. 2001.

[34] D. Li et al., "On lightning electromagnetic field propagation along an irregular terrain," IEEE Trans. Electromagn. Compat., vol. 58, no. 1, pp. 161-171, Feb. 2016.

[35] A. Shoory, F. Rachidi, M. Rubinstein, R. Moini, and S. H. H. Sadeghi, "Why do some lightning return stroke models not reproduce the far-field zero crossing?", J. Geophys. Res., vol. 114, 2009, Art. no. D16204.

[36] A. Mosaddeghi et al., "Radiated fields from lightning strikes to tall structures: Effect of upward-connecting leader and reflections at the return stroke wavefront," IEEE Trans. Electromagn. Compat., vol. 53, no. 2, pp. 437-445, May 2011.

[37] F. Heidler, "Traveling current source model for LEMP calculation," in Proc. 6th Int. Zurich Symp. Electromagn. Compat., 1985, pp. 157-162.

[38] J. Bermudez, C. Pena-Reyes, F. Rachidi, and F. Heidler, "Use of genetic algorithms to extract primary lightning current parameters," presented at the EMC Eur. Int. Symp. Electromagn. Compat., Sorrento, Italy, 2002.

[39] D. M. Le Vine and R. Meneghini, "Electromagnetic fields radiated from a lightning return stroke: Application of an exact solution to Maxwell's equations," J. Geophys. Res., vol. 83, pp. 2377-2384, 1978.

[40] M. Rubinstein and M. A. Uman, "On the radiation field turn-on term associated with traveling current discontinuities in lightning," J. Geophys. Res. vol. 95, pp. 3711-13, 1990.

[41] M. Rubinstein and M. A. Uman, "Transient electric and magnetic fields associated with establishing a finite electrostatic dipole, revisited," IEEE Trans. Electromagn. Compat., vol. 33, no. 4, pp. 312-320, Nov. 1991.

[42] D. M. Le Vine and J. C. Willett, "Comment on the transmission line model for computing radiation from lightning," J. Geophys. Res., vol. 97, pp. 2601-2610, 1992

[43] R. Thottappillil and V. A. Rakov, "On different approaches to calculating lightning electric fields," J. Geophys. Res., vol. 106, pp. 14191-14205, 2001.

[44] R. Thottappillil and V. A. Rakov, "On the computation of electric fields from a lightning discharge in time domain," presented at IEEE EMC Int. Symp., Montreal, Que., Canada, Aug. 13-17, 2001.

[45] R. Thottappillil, V. A. Rakov, and M. A. Uman, "Distribution of charge along the lightning channel: Relation to remote electric and magnetic fields and to return-stroke models," J. Geophys. Res., vol. 102, pp. 6987-7006, 1997.

[46] R. Thottappillil, M. A. Uman, and V. A. Rakov, "Treatment of retardation effects in calculating the radiated electromagnetic fields from the lightning discharge," J. Geophys. Res., vol. 103, pp.9003-9013, 1998.

[47] D. Pavanello, F. Rachidi, M. Rubinstein, J. L. Bermudez, and C. A. Nucci, "Electromagnetic field radiated by lightning to tall towers: Treatment of the discontinuity at the return stroke wave front," J. Geophys. Res., vol. 109, 2004, Art. no. D06114

[48] W. Shangguan et al., "A China data set of soil properties for land surface modeling," J. Adv. Model. Earth Syst., vol. 5, pp. 212-224, 2013.

[49] G. Yang, Z. Yu, Y. Zhang, S. Chen, B. Zhang, and J. He, "Evaluation of lightning current and return stroke velocity using measured far electric field above a horizontally stratified ground," IEEE Trans. Electromagn. Compat., vol. 59, no. 6, pp. 1940-1948, Dec. 2017.

[50] Word atlas of ground conductivities, Rec. ITU-R P.832-2, 1999. [Online]. Available: http://hamwaves.com/ground/en/index.html

[51] M. A. Uman and D. K. McLain, "Magnetic field of lightning return stroke," J. Geophys. Res., vol. 74, pp. 6899-6910, 1969.

[52] V. Rakov and A. Dulzon, "A modified transmission line model for lightning return stroke field calculations," in Proc. 9th Int. Symp. Electromagn. Compat, 1991, pp. 229-235

[53] C. Nucci, G. Diendorfer, M. Uman, F. Rachidi, M. Ianoz, and C. Mazzetti, "Lightning return stroke current models with specified channel-base current: A review and comparison," J. Geophys. Res., vol. 95, pp. 2039520408, 1990.

[54] F. Rachidi and R. Thottappillil, "Determination of lightning currents from far electromagnetic fields," J. Geophys. Res., vol. 98, pp. 18315-18321, 1993

[55] X.-M. Shao, E. Lay, and A. R. Jacobson, "On the behavior of return stroke current and the remotely detected electric field change waveform," J. Geophys. Res., vol. 117, 2012, Art. no. D07105.
[56] G. Lupò, C. Petrarca, V. Tucci, and M. Vitelli, "EM Fields Generated by Lightning Channels with Arbitrary Location and Slope," IEEE Trans. Electromagn. Compat., vol. 42, no. 1, pp. 39-53, Feb. 2000.

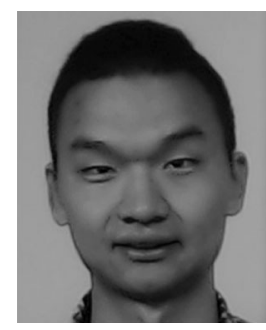

Quanxin Li was born in Huanggang City, Hubei Province, China, in 1991. He received the B.Sc. degree in electrical engineering in 2014 from China Three Gorges University, Yichang, China, where he is currently working toward the Ph.D. degree in electrical engineering at Wuhan University, Wuhan, China, since 2014.

From 2017, he is a Visiting Student with EMC Lab, Swiss Federal Institute of Technology, Lausanne, Switzerland. His research interests include lightning detection and lightning protection.

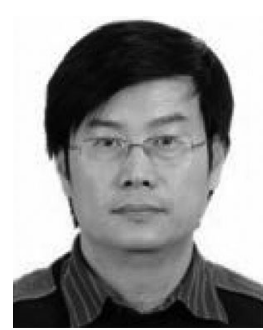

Jianguo Wang (M'10) was born in Xiaogan City, Hubei Province, China, in 1968. He received the M.Sc. and Ph.D. degrees in high-voltage and insulation technology from Wuhan University, Wuhan, China, in 1998 and 2004, respectively.

He is currently a Professor with the School of Electrical Engineering, Wuhan University. His research interests include lightning protection and grounding technology, high-voltage insulation and measurement technology, and electromagnetic compatibility in power systems.

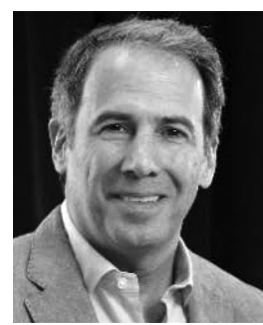

Farhad Rachidi (M'93-SM'02-F'10) received the M.S. degree in electrical engineering and the Ph.D. degree in electrical engineering from the Swiss Federal Institute of Technology, Lausanne, Switzerland, in 1986 and 1991, respectively.

He was with the Power Systems Laboratory, Swiss Federal Institute of Technology, until 1996. In 1997, he joined the Lightning Research Laboratory, University of Toronto, Toronto, ON, Canada. From 1998 to 1999, he was with Montena EMC, Rossens, Switzerland. He is currently a Titular Professor and the Head of the EMC Laboratory with the Swiss Federal Institute of Technology, Lausanne, Switzerland. He has authored or coauthored more than 170 scientific papers published in peer-reviewed journals and more than 350 papers presented at international conferences.

Dr. Rachidi is currently a member of the Advisory Board of the IEEE TRANSACTIONS ON ELECTROMAGNETIC COMPATIBILITY and the President of the Swiss National Committee of the International Union of Radio Science. He was the recipient of numerous awards including the 2005 IEEE Transactions on Electromagnetic Compatibility Technical Achievement Award, the $2005 \mathrm{CI}$ GRE Technical Committee Award, the 2006 Blondel Medal from the French Association of Electrical Engineering, Electronics, Information Technology and Communication, the 2016 Berger Award from the International Conference on Lightning Protection, the 2016 Best Paper Award of the IEEE TRANSACTIONS ON ELECTROMAGNETIC COMPATIBILITY, and the 2017 Motohisa Kanda Award for the most cited paper of the IEEE Transactions on Electromagnetic Compatibility. In 2014, he was conferred the title of Honorary Professor of the Xi'an Jiaotong University, Xi' an, China. He was the Vice-Chair of the European COST Action on the Physics of Lightning Flash and Its Effects from 2005 to 2009 , the Chairman of the 2008 European Electromagnetics International Symposium, the President of the International Conference on Lightning Protection from 2008 to 2014, the Editor-in-Chief for the Open Atmospheric Science Journal (2010-2012) and the Editor-in-Chief for the IEEE TRANSACTIONS ON Electromagnetic CompatibiLity from 2013 to 2015. He is a Fellow of the SUMMA Foundation and a member of the Swiss Academy of Sciences. 


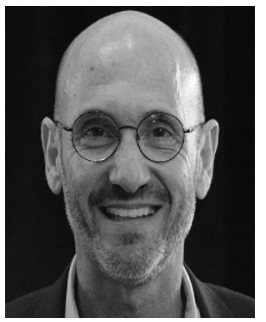

Marcos Rubinstein (M'84-SM'11-F'14) received the master's and Ph.D. degrees in electrical engineering from the University of Florida, Gainesville, FL, USA, in 1986 and 1991, respectively.

In 1992, he joined the Swiss Federal Institute of Technology, Lausanne, Switzerland, where he was involved with the fields of electromagnetic compatibility and lightning. In 1995, he was with Swisscom, where he worked on numerical electromagnetics and EMC. In 2001, he joined the University of Applied Sciences of Western Switzerland HES-SO, Yverdonles-Bains, where he is currently a Full Professor, Head of the advanced Communication Technologies Group, and a member of the IICT Institute Team. He is the author or coauthor of more than 200 scientific publications in reviewed journals and international conferences. He is also the coauthor of seven book chapters..

Dr. Rubinstein was the recipient of the best Master's Thesis Award from the University of Florida, IEEE achievement award, and also a co-recipient of the NASA's Recognition for Innovative Technological Work Award. He is a Fellow of the SUMMA Foundation, a member of the Swiss Academy of Sciences and of the International Union of Radio Science. He is the Chairman of the International Project on Electromagnetic Radiation from Lightning to Tall structures. He was the Editor-in-Chief for the Open Atmospheric Science Journal, and currently an Associate Editor for the IEEE TRANSACTIONS ON ELECTROMAGNETIC COMPATIBILITY

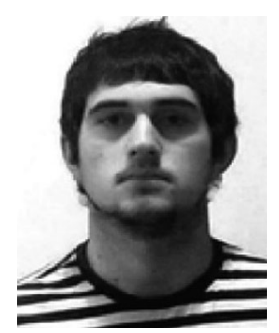

Antonio Šunjerga received the M.Sc. degree in communication and information technology and B.Sc. degree in Physics, both from the University of Split, Split, Croatia, both in 2017. He is currently working toward the Ph.D. degree in electrical engineering at the Electromagnetic Compatibility Laboratory, Swiss Federal Institute of Technology of Lausanne, Lausanne, Switzerland.

His research interests include lightning and electromagnetic compatibility.

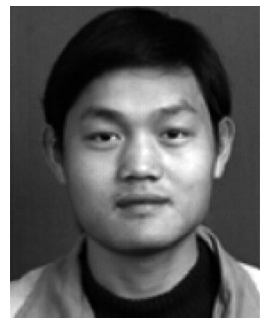

Li Cai was born in Wuxue City, Hubei Province, China, in 1987. He received the B.Sc. degree in electrical engineering and automation from Wuhan University, Wuhan, China, in 2008, and the Ph.D. degree in high-voltage and insulation technology, Wuhan University, in 2013.

$\mathrm{He}$ is currently an Associate Professor with the School of Electric Engineering, Wuhan University. $\mathrm{He}$ was a Visiting Scholar with Texas A\&M University, College Station, TX, USA, during 2015-2016. and lightning protection. His research interests focuses on lightning detection

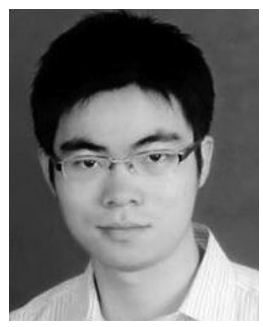

Mi Zhou (M'14) was born in Ezhou City, Hubei Province, China, in 1986. He received the B.Sc. and $\mathrm{Ph} . \mathrm{D}$. degrees in high-voltage and insulation technology from Wuhan University, Wuhan, China, in 2006 and 2012, respectively.

$\mathrm{He}$ is currently an Associate Professor with the School of Electric Engineering, Wuhan University. He was a Visiting Scholar with Gifu University, Gifu, Japan, during 2014-2015. His research interests include high-voltage measurement, lightning protection and grounding technology, and electromagnetic compatibility. 